\title{
CAPACITADORES DO CONHECIMENTO E ESTRATÉGIAS DE SOBREVIVÊNCIA E AVANÇO PARA O AUMENTO DA COMPETITIVIDADE: ESTUDO EM UMA MULTINACIONAL DO SETOR ALIMENTÍCIO.
} RESUMO

O objetivo principal deste artigo é apresentar os resultados da pesquisa realizada para identificar e analisar as contribuições dos capacitadores do conhecimento e das estratégias de sobrevivência e avanço para a competitividade de uma multinacional do setor alimentício. Foi realizado um estudo de caso descritivo. A coleta de dados foi feita por meio da aplicação de questionário a 219 colaboradores da empresa e entrevista individual com um gestor da alta gerência. Os dados quantitativos e qualitativos coletados foram analisados à luz do modelo teórico de Von Krogh, Ichijo \& Nonaka (1998). Os resultados apontaram a presença dos cinco capacitadores do conhecimento e das estratégias de sobrevivência e avanço evidenciando suas contribuições para a competitividade da multinacional. Os capacitadores "instilar a visão do conhecimento", "gerenciar as conversas" e "identificar os ativistas do conhecimento" mostraram contribuições importantes para a competitividade. Os capacitadores "criar o contexto adequado" e "globalizar o conhecimento local" representam pontos de melhoria. Os resultados da pesquisa sinalizaram que a empresa está atenta ao ambiente competitivo e desenvolve estratégias para garantir sua sobrevivência e avanço.

Palavras-chave: Gestão do conhecimento, Capacitadores do conhecimento; Estratégias de sobrevivência e avanço; Competitividade.

\section{KNOWLEDGE ENABLERS AND STRATEGIES OF SURVIVAL AND DEVELOPMENT USED TO INCREASE COMPETITIVENESS: A CASE STUDY IN A MULTINATIONAL COMPANY OF THE FOOD SECTOR} ABSTRACT

The main objective of this paper is to present the results of a research carried out to identify and analyze the contributions of the knowledge enablers and strategies of survival and development to the competitiveness of a multinational company of the food sector. For this purpose it was conducted a descriptive case study. Data collection was done through a questionnaire answered by 219 workers and an interview with a senior management officer. Quantitative and qualitative data were analyzed based on the theoretical model of Von Krogh, Ichijo and Nonaka (1998). The results showed the presence of the five knowledge enablers and strategies of survival and development indicating their contributions to the competitiveness of the company. The knowledge enablers "promotion of a knowledge vision," "managing conversations" and "identifying the knowledge activists" showed important contributions to company competitiveness. The knowledge enablers "creation the right context" and "globalizing local knowledge" were considered points for improvement. The research results indicate that the company is aware of the competitive environment and creates strategies to ensure its survival and development.

Keywords: Knowledge Management, Knowledge Enablers; Survival and Development Strategies; Competitiveness.

\footnotetext{
${ }^{1}$ Fundação Pedro Leopoldo - FPL, Brasil

E-mail: michele.silva@pepsico.com

${ }^{2}$ Fundação Pedro Leopoldo - FPL, Brasil

E-mail: celestevasconcelos@gmail.com

${ }^{3}$ Fundação Pedro Leopoldo - FPL, Brasil

E-mail: eejeunon@gmail.com

${ }^{4}$ Fundação João Pinheiro - FJP, Brasil

E-mail: $\underline{\text { sduf@uol.com.br }}$
} 
Capacitadores do Conhecimento e Estratégias de Sobrevivência e Avanço para o Aumento da Competitividade: Estudo em uma Multinacional do Setor Alimentício.

\section{INTRODUÇÃO}

Atualmente, a necessidade de manter e criar um diferencial competitivo entre as organizações se torna cada vez maior. Fica evidente a consciência de que o recurso gerado e utilizado, capaz de garantir o desenvolvimento das organizações por meio da geração de vantagem competitiva, é o conhecimento. Em consequência, o gerenciamento do conhecimento de forma produtiva tem se tornado uma prática relevante $\mathrm{e}$ indispensável. É a partir desse cenário que surge a gestão do conhecimento.

A gestão do conhecimento é um modelo de gerenciamento das organizações focado na aprendizagem, na geração e aquisição contínuas de conhecimento, no seu compartilhamento e uso. Observa-se que muitas instituições não conhecem a expressão gestão do conhecimento, todavia executam os processos, realizam práticas e utilizam ferramentas próprias dela (Gonçalves, 2010).

No Brasil, a gestão do conhecimento tornou-se mais presente a partir da década de 1990 e são vários os pesquisadores que têm se dedicado ao tema (Pereira et al. 2015; Braga et al. 2014, Alvarenga Neto et al. 2013; Gonçalves et al. 2012; Terra, 2005, Vasconcelos, 2000).

Alguns autores se dedicaram a pesquisar principalmente à fase da criação do conhecimento, como novo recurso de competitividade. Von Krogh et al. (2001) afirmam que, para que o processo de criação do conhecimento ocorra nas organizações, é necessário que esteja amparado pelos capacitadores do conhecimento, sendo estes: instilar a visão do conhecimento, gerenciar as conversas, mobilizar os ativistas do conhecimento, criar o contexto adequado e globalizar o conhecimento local. Os autores ressaltam a necessidade das organizações definirem estratégias de sobrevivência e de avanço. As primeiras garantem a manutenção da posição já conquistada da organização no mercado; as segundas proporcionam o crescimento futuro fortalecendo as vantagens competitivas da organização. O processo do desenvolvimento de uma estratégia em uma organização, seja de sobrevivência ou avanço, ocorre a partir da relação direta com os capacitadores do conhecimento e permite que os indivíduos explorem territórios desconhecidos em novos mercados, novos clientes, criem novos produtos e desenvolvam novas tecnologias de fabricação. Assim, a organização adquire flexibilidade e se volta para o futuro, podendo se tornar uma empresa mais rentável a curto e longo prazo.

Nesse contexto da criação do conhecimento como diferencial competitivo e considerando as contribuições de Von Krogh et al. (2001), o foco desta pesquisa foi dirigido à identificação dos capacitadores do conhecimento e das estratégias e como eles contribuem para o aumento da competitividade em uma empresa do setor alimentício.

A empresa pesquisada, a PepsiCo do Brasil, faz parte de uma rede global com negócios em mais de 200 países e que chegou ao país em 1953 por meio da marca Pepsi-Cola. No Brasil, a PepsiCo possui 18 fábricas, estrategicamente localizadas em todo o território nacional, com aproximadamente 200 filiais de vendas e com cerca de 12.000 mil funcionários. Considerando a hierarquia da empresa no Brasil, ela está fundamentada em duas divisões - alimentos e bebidas -, cada uma com seus respectivos presidentes.

A PepsiCo declara que possui uma visão de negócios de "Performance com Propósito" que equivale ao crescimento com sólido desempenho financeiro que retorna para sociedade com produtos saudáveis, apoio a um estilo de vida mais equilibrado e eficiente uso dos recursos naturais. A empresa ainda ressalta que, na busca pelo crescimento sustentável, estimula a inovação, valoriza os resultados e procura entender se as ações de hoje contribuirão para futuro.

Apesar da existência na literatura de vários estudos sobre gestão do conhecimento, não foram encontradas pesquisas abordando a relação entre competitividade, capacitadores do conhecimento e estratégias de sobrevivência e avanço que tivessem sido efetuados em uma multinacional do segmento alimentício.

Com base no contexto descrito, o objetivo principal desta pesquisa foi identificar e analisar as contribuições dos capacitadores do conhecimento e das estratégias de sobrevivência e avanço para a competitividade da PepsiCo.

Outros objetivos definidos foram: pesquisar na literatura os principais modelos de gestão do conhecimento e sua relação com a competitividade; identificar os capacitadores do conhecimento na empresa; mapear e descrever as estratégias de sobrevivência e avanço utilizadas; verificar se os capacitadores do conhecimento e os referenciais estratégicos mapeados na empresa contribuem para sua competitividade.

$\mathrm{O}$ artigo foi estruturado em cinco tópicos; iniciando por esta Introdução, que apresenta os objetivos da pesquisa. No segundo tópico são apresentados os principais conceitos que envolvem a Gestão do Conhecimento, ressaltando-se o modelo de Von Krogh et al. (2001), marco teórico da pesquisa. Segue a metodologia utilizada para atingir o objetivo (terceiro tópico) e os resultados obtidos (quarto tópico). $\mathrm{O}$ último tópico apresenta as considerações finais e conclusões da pesquisa. 
Capacitadores do Conhecimento e Estratégias de Sobrevivência e Avanço para o Aumento da Competitividade: Estudo em uma Multinacional do Setor Alimentício.

\section{REFERENCIAL TEÓRICO}

A partir da crescente valorização do conhecimento, provocada pelo advento da sociedade do conhecimento, o conceito de gestão do conhecimento emerge. Em sua prática e essência, essa gestão visa desenvolver nas organizações estratégias para uso intensivo do conhecimento tornando-o um diferencial competitivo.

\section{O conhecimento organizacional}

Partindo das considerações de Crawford (1994), conhecimento é entendimento e "expertise", além de ser a capacidade de aplicar a informação a um trabalho ou resultado específico. Esse conhecimento se produz nas mentes das pessoas que trabalham nas organizações. À medida que os conhecimentos são estimulados, vão se disseminando, podendo " $[$...] estar embutido[s] não só em documentos ou repositórios mas também em rotinas, processos, práticas e normas organizacionais" (Davenport e Prusak, 1998, p. 6).

Entende-se como criação do conhecimento organizacional a possibilidade de a organização criar, difundir e absorver um novo conhecimento para utilização em seus processos ou produtos (Nonaka e Takeuchi, 1997, p. 1). Na mesma linha, Choo (1998) reforça que da construção do conhecimento resultam novos conhecimentos que levam a inovações, novos produtos e novas capacidades organizacionais. $\mathrm{O}$ conhecimento do homem se transformou em fator fundamental na sociedade atual e "administrá-lo encontrar e estimular o capital intelectual, armazená-lo, vendê-lo e compartilhá-lo - tornou-se a tarefa econômica mais importante dos indivíduos, das empresas e dos países" (Stewart, 1998, p. 11).

Von Krogh et al (2001) afirmam que o conhecimento é definido como uma crença verdadeira e justificada, podendo ser explícito ou tácito, além de depender de um contexto capacitante. Em linhas gerais, as mudanças decorrentes da sociedade do conhecimento e o aumento da necessidade da vantagem competitiva instigam as organizações a formarem um ambiente facilitador para a criação do conhecimento organizacional; surgindo como uma resposta a esse movimento à gestão do conhecimento.

\section{A Importância da gestão do conhecimento}

Nesse processo de gerir o conhecimento, Nonaka e Takeuchi (1997) reforçam a importância da criação, codificação e aplicação do mesmo, principalmente para inovar em produtos e serviços nas organizações. Os autores ressaltam que, para que esse processo ocorra, há necessidade da criação de espaços para interação social entre o conhecimento tácito e explícito. O conhecimento tácito é considerado pessoal, específico do contexto da pessoa e de difícil comunicação; o explícito é considerado transmissível e de possível codificação. O processo espiral sugerido pelos autores possibilita a externalização do conhecimento, que gera a internalização e a passagem do conhecimento tácito em explícito e do explícito em tácito.

Probst, Raub e Romhart (2002) complementam as ideias de Nonaka e Takeuchi enfatizando que a realização do gerenciamento do conhecimento consiste em identificar, adquirir, desenvolver, compartilhar, utilizar e incentivar a retenção do conhecimento. Von Krogh et al (2001) reforçam este conceito complementando que a eficácia da gestão do conhecimento depende da criação do contexto capacitante, considerado um espaço compartilhado para alimentar novos relacionamentos. Partindo do conceito de $b a$, ou seja, "lugar", o contexto organizacional pode ser virtual, físico ou mental. O conhecimento é dinâmico e relacional por resultar da ação humana e, ao contrário das informações e dados, depende do contexto para ser criado. Assim, "dir-se-ia que o conhecimento é inerente ao $b a$, e que o fomento de todo o processo de criação do conhecimento exige o necessário contexto ou espaço do conhecimento" (Von Krogh et al. 2001, p. 16).

As organizações exercem um papel relevante na criação de contextos que estimulem o compartilhamento do conhecimento, tornando-o acessível e facilitando o aprendizado coletivo. Nesse processo é importante gerir de forma eficaz ferramentas, métodos e processos para estimular seu desenvolvimento, compartilhamento e proteção mantendo o foco na competitividade.

\section{Gestão do conhecimento e competitividade}

Nonaka e Takeuchi (1997) relacionam a criação do conhecimento ao fator da inovação contínua e da vantagem competitiva. Segundo os autores, quando difundido na organização, o conhecimento organizacional criado é incorporado a produtos, serviços e sistemas, gerando inovação contínua e proporcionando vantagem competitiva. Von Krogh et al. (2001) complementam que alguns fatores na criação do conhecimento organizacional são preponderantes na manutenção da vantagem competitiva sustentável. Para eles, a gestão do conhecimento deve ser baseada na aplicação de processos de criação contínuos, através dos quais os novos conhecimentos criados irão compor a base de obtenção de novas vantagens.

Alvarenga Neto et al. (2007) realizaram uma pesquisa em três empresas, de diferentes portes, que apresentam programas de gestão do conhecimento. Foram realizadas entrevistas com gestores no intuito de identificar a percepção destes sobre a gestão do conhecimento e a competitividade nas organizações às quais pertenciam. Os autores concluíram por meio da pesquisa que, de fato, a informação e o conhecimento 
Capacitadores do Conhecimento e Estratégias de Sobrevivência e Avanço para o Aumento da Competitividade: Estudo em uma Multinacional do Setor Alimentício.

se constituem nos principais fatores de competitividade dos tempos atuais para as organizações e nações.

A pesquisa de Cardoso (2007) também focou a relação entre a gestão do conhecimento e a competividade e teve como objetivo avaliar a capacidade preditiva dos processos de gestão do conhecimento organizacional frente aos resultados obtidos pelas organizações através do conjunto de indicadores de competitividade. $\mathrm{O}$ autor utilizou um modelo de equações estruturais, que permitiu testar a validade do modelo teórico utilizado, segundo o qual a gestão do conhecimento promove a competitividade organizacional. Em suas constatações, a partir das múltiplas regressões realizadas, o autor concluiu "que existe uma elevada relação direta entre a gestão do conhecimento e a competitividade organizacional, traduzida na existência de um impacto positivo da primeira na segunda" (Cardoso, 2007, p. 208).

Na mesma linha, Santos e Popadiuk (2010) também realizaram uma pesquisa, em oito empresas, nacionais e multinacionais, coletando os dados através de entrevistas não estruturadas. A pesquisa buscou identificar, segundo a percepção dos gestores, se os benefícios das práticas de gestão do conhecimento são associados com a capacidade competitiva das empresas. Os resultados alcançados retratam "evidências de que nas empresas estudadas os gestores reconhecem uma associação entre as práticas de gestão do conhecimento e a aquisição de uma vantagem competitiva" (Santos e Popadiuk, 2010, p. 21).

Considerando as pesquisas apresentadas, podese constatar que há o reconhecimento da ligação da gestão do conhecimento com a geração e manutenção de vantagem competitiva.

\section{O modelo de Von Krogh, Ichijo e Nonaka}

O modelo proposto por Von Krogh et al. (2001) considera que, para o conhecimento ser utilizado como vantagem competitiva nas organizações, a criação do conhecimento deve fazer parte de seu referencial estratégico, com ênfase nas estratégias de sobrevivência e avanço. As estratégias são imprescindíveis e complementares às organizações, sendo que as de sobrevivência atuam na exploração do conhecimento para manter seu atual nível de sucesso e desempenho e as de avanço agem na melhoria do desempenho para o futuro.

A estratégia de sobrevivência é voltada para a rentabilidade da organização no presente e em curto prazo, sendo seu objetivo garantir o domínio sobre o cenário atual dos negócios. Esse domínio é garantido através da redução do potencial de negociação dos atuais fornecedores e clientes, com uso do bom posicionamento de mercado em comparação aos concorrentes, atendendo às necessidades dos stakeholders envolvidos. Para manter as estratégias de sobrevivência, as organizações buscam dificultar a entrada de novos concorrentes no mercado. Caso surjam possíveis produtos substitutos, utilizam-se os efeitos da experiência e/ou economias de escopo, via conhecimento, como ferramenta capaz de atender às necessidades presentes.

As estratégias de avanço visam proporcionar a rentabilidade da organização no futuro, além de contribuir para o aumento de sua competitividade. Elas permitem reforçar os pontos fortes e eliminar os pontos fracos na futura base de recursos e conhecimento da empresa. O objetivo é tirar proveito de futuras oportunidades de negócios na busca da diminuição dos impactos gerados por ameaças de transição contínua e posicionamento de produto-mercado. As organizações, por meio das estratégias de avanço, devem formar alianças estratégicas com instituições de pesquisa, desenvolver padrões tecnológicos e construir fortes vínculos com futuros fornecedores e clientes. Também por meio delas, as organizações podem identificar os concorrentes potenciais e as reações à criação de novos conceitos de produtos e serviços, bem como melhorar o posicionamento de seus produtos no mercado frente à competitividade deste.

A utilização das duas estratégias proporciona vantagens competitivas distintas, bem como demandas de conhecimentos diferentes de acordo com os processos aos quais estão associadas, porém o equilíbrio adequado e igual atenção entre elas são fundamentais.

Os autores ressaltam a importância do desenvolvimento do contexto capacitante e sugerem cinco capacitadores do conhecimento, que não se enquadram em uma sequência determinada, mas que contribuem para que a estratégia adotada se desenvolva. São eles:

Capacitador 1 Instilar a visão do conhecimento é responsável por estimular a formação de microcomunidades, nivelar o conhecimento e contribuir para a criação de conceitos e de protótipos, além da liberação do conhecimento tácito, que pode impulsionar a inovação e gerar a visão adequada do conhecimento. A partir da interação social na perspectiva construcionista da visão do conhecimento, os gerentes devem reinventar e reinvestigar suas atuais crenças.

Capacitador 2 - Gerenciar as conversas visa promover a criatividade na organização por meio de conversas encorajando a participação de todos. A partir da troca de ideias, opiniões e crenças, as conversas proporcionam o principal passo da criação do conhecimento, que é o compartilhamento tácito dentro das microcomunidades. Estes podem ser transformados em protótipos de produtos e serviços a serem utilizados no futuro, gerando sucesso para uma organização.

Capacitador 3 - Mobilizar os ativistas do conhecimento visa capacitar e criar a presença de catalizadores do conhecimento, que formam as microcomunidades de conhecimento e facilitam a 
Capacitadores do Conhecimento e Estratégias de Sobrevivência e Avanço para o Aumento da Competitividade: Estudo em uma Multinacional do Setor Alimentício.

trajetória para a criação e justificação dos conceitos, assim como o desenvolvimento de protótipos. As tarefas dos ativistas podem variar de acordo com circunstâncias específicas do negócio, contudo, em geral existem três papéis principais: atuar como catalisadores da criação do conhecimento, coordenadores dos programas de criação do conhecimento e sinalizadores da trajetória geral para a criação de conhecimento entre as diferentes microcomunidades.

Capacitador 4 - Criar o contexto adequado busca estruturar a organização de modo que a criação do conhecimento em seu ambiente seja mais eficaz e eficiente, ultrapassando todas as barreiras pessoais e organizacionais que possam existir. $\mathrm{O}$ contexto capacitante é o fator que estimula a criação do conhecimento, também conhecido como ba, que se refere ao contexto certo. O ba é caracterizado pela rede, presencial ou virtual, de interações entre as pessoas unificando os espaços mentais dos envolvidos da criação do conhecimento. Algumas organizações enfrentam um conjunto de barreiras e nem sempre conseguem criar um contexto capacitante. Existem, por exemplo, contextos hipercompetitivos que dificultam esse processo. Para obter um contexto realmente capacitante, o ambiente social deve proporcionar o avanço da criação individual ou coletiva, caso contrário será apenas uma interação social.

Capacitador 5 - Globalizar o conhecimento local visa proporcionar a difusão do conhecimento local em toda a organização, proporcionando a nivelação do conhecimento. Um requisito importante para seu desenvolvimento é o rompimento das barreiras físicas, culturais, organizacionais e gerenciais, que podem comprometer a eficácia da transferência do conhecimento. O processo de globalização do conhecimento local garantirá que o conhecimento certo se torne acessível às pessoas ou grupos certos numa grande empresa, e que o conhecimento original seja recriado sob outra forma, proporcionando outra rodada de inovações. À medida que as várias unidades usam o conhecimento e o adaptam às suas circunstâncias locais, a vantagem competitiva cresce para toda a organização.

O próximo item apresenta a metodologia utilizada para se atingir o objetivo da pesquisa.

\section{METODOLOGIA}

A partir da teorização apresentada, a pesquisa utilizou por base teórica principalmente o modelo de Von Krogh et al. (2001), pois o objetivo principal foi identificar e analisar as contribuições dos capacitadores do conhecimento e das estratégias de sobrevivência e avanço para a competitividade. A pesquisa realizada constituiu de um estudo de caso descritivo, pois buscou identificar e analisar as contribuições desses capacitadores e dessas estratégias para a competitividade na Empresa (Yin, 2001).

Foram utilizadas as abordagens quantitativa e qualitativa, considerando o pressuposto de que as duas abordagens são complementares (Collis e Hussey, 2005).

Como instrumentos de coleta de dados, foram elaborados: um questionário com 30 questões e um roteiro de entrevista, com o objetivo de abranger os cinco constructos e as duas dimensões estratégicas, que se pretendia investigar. No questionário foi usado a escala Likert, variando de 1(hum) a 5(cinco), onde 1 representava concordância total e 5 discordância total. Portanto, os valores abaixo de 3 (três) tendiam à concordância.

A unidade de análise foi a empresa do setor de alimentos PepsiCo, que possui atualmente doze mil colaboradores. A unidade de observação quantitativa foi composta por 219 funcionários e a qualitativa pelo gerente da área de vendas. A área de vendas é a de maior representatividade na Empresa. Os respondentes foram escolhidos pelo critério de acessibilidade.

Foi também realizada pesquisa documental, em documentos da Empresa. Portanto, na coleta de dados foram utilizados dados primários e secundários (Collis e Hussey, 2005).

Como estratégia de análise dos dados, da pesquisa quantitativa utilizou-se os softwares $R$ Core Team direcionado para pesquisas com escala Likert e o SmartPLS 2.0. direcionado para análise de confiabilidade e estatística descritiva. Na pesquisa qualitativa foi realizada análise de conteúdo (Bardin, 2009). Os dados obtidos na aplicação do questionário e na entrevista foram analisados conforme o modelo de Von Krogh et al. (2001).

Em relação à divisão de níveis utilizada na pesquisa, foi considerada a nomenclatura já aplicada e reconhecida na empresa, sendo:

- "frontline" - para cargos operacionais;

- "nível L01 a L05" - para cargos de assistentes e analistas e

- "nível L06 e acima" - para cargos gerenciais.

Para a localidade, foi utilizado:

- O nome EC/Rochaverá, que representa a matriz, sendo chamada por todos os funcionários de escritório central.

- A sigla $C D V$, para representar os centros de distribuição de vendas, ou seja, unidades responsáveis pela operacionalização da área de vendas.

- A localidade fábrica é utilizada para indicar as unidades responsáveis pela fabricação de produtos.

- O termo outros foi utilizado para o restante dos respondentes, pertencentes a 
Capacitadores do Conhecimento e Estratégias de Sobrevivência e Avanço para o Aumento da Competitividade: Estudo em uma Multinacional do Setor Alimentício.

localidades diferentes das três principais, acima citadas.

\section{RESULTADOS OBTIDOS}

Este capítulo apresenta os resultados encontrados na pesquisa, de acordo com os objetivos propostos.

O perfil dos respondentes ficou assim definido:

- Área de atuação: 57\% atuam na área de vendas, $24 \%$ na administrativa, $9 \%$ em operações e $10 \%$ em outras áreas.

- Local de trabalho: 66\% estão nos Centros de Distribuição de Vendas (CDV), $14 \%$ na fábrica, $10 \%$ no Escritório Central (EC) e $10 \%$ em outros locais da empresa.

- Cargo: $55 \%$ são do frontline, $24 \%$ do nível L01 a L05 (assistentes e analistas) e 21\% nível L06 e acima, representando os gestores da empresa.

- Idade: $43 \%$ possuem entre 31 a 40 anos, $32 \%$ entre 21 a $30,20 \%$ entre 41 e 50 , não tendo sido encontrados respondentes acima de 60 anos.

- Escolaridade: $45 \%$ possuem ensino médio, $32 \%$ ensino superior e $22 \%$ com especialização e MBA. $1 \%$ têm doutorado e para o mestrado e o ensino fundamental não houve representatividade.

\section{Identificação dos capacitadores do conhecimento}

O primeiro objetivo da pesquisa foi identificar a presença ou não dos capacitadores do conhecimento na Empresa. A Tabela 1 apresenta as questões utilizadas para esta análise. Verificou-se que os capacitadores tiveram média de 2,5 a 3 , um resultado próximo a concordância parcial sinalizando que todos estão presentes, uns com mais intensidade que outros.

Considerando a média de todas as questões para identificação de cada capacitador, observou-se que aquele que possui a maior propensão à concordância é o capacitador "Mobilizar os Ativistas do Conhecimento" com a média de 2,6, mediana de 2,0, podendo ser considerado o capacitador mais forte da organização. Por outro lado, o capacitador Globalizar o Conhecimento Local apresentou maior proximidade com o resultado nem concordo e nem discordo, indicando que os respondentes não confirmam a presença do capacitador, porém também não discordam da possibilidade de sua existência (média de 2,9 e mediana de 2,8). Assim, aponta-se esse capacitador como uma oportunidade de melhoria para a organização.

Analisando o resultado da média de todas as questões em proximidade da mediana, destaca-se a questão 1 "sinto-me a vontade para expressar minhas ideias, opiniões e crenças com as pessoas da organização". Este resultado (2,3 de média e 2,0 para mediana) revela que "a livre expressão de ideias dos funcionários é presente na organização".

Tabela 1 - Estatísticas descritivas dos capacitadores do conhecimento

\begin{tabular}{|l|c|c|c|}
\hline & Média & Mediana & $\begin{array}{c}\text { Desvio- } \\
\text { padrão }\end{array}$ \\
\hline Capacitador 1: Instilar a Visão do Conhecimento & $\mathbf{2 , 8}$ & $\mathbf{2 , 3}$ & $\mathbf{1 , 5}$ \\
\hline $\begin{array}{l}\text { 2. Sempre sou estimulado por compartilhar os meus conhecimentos com } \\
\text { outros membros da organização. }\end{array}$ & 2,5 & 2 & 1,4 \\
\hline $\begin{array}{l}\text { 3. Dentro da organização sou envolvido em discussões contendo temas que } \\
\text { envolvem assuntos para além do escopo da minha função. }\end{array}$ & 3,0 & 3 & 1,5 \\
\hline $\begin{array}{l}\text { 4. Minha liderança geralmente comunica ideias e valores positivos que me } \\
\text { estimulam a sentir bem em relação ao meu cargo. }\end{array}$ & 2,6 & 2 & 1,4 \\
\hline $\begin{array}{l}\text { 5. A organização busca me indicar como ter a visão de me deslocar do } \\
\text { presente para o futuro. }\end{array}$ & 2,8 & 2 & 1,5 \\
\hline Capacitador 2 - Gerenciar as Conversas & $\mathbf{2 , 7}$ & $\mathbf{2 , 5}$ & $\mathbf{1 , 5}$ \\
\hline $\begin{array}{l}\text { 1. Sinto-me a vontade para expressar minhas ideias, opiniões e crenças com } \\
\text { as pessoas da organização. }\end{array}$ & 2,3 & 2 & 1,4 \\
\hline $\begin{array}{l}\text { 6. Minha liderança estimula discussões baseadas em dados do presente com } \\
\text { o objetivo de solucionar problemas de forma eficaz. }\end{array}$ & 2,7 & 2 & 1,5 \\
\hline $\begin{array}{l}\text { 7. Geralmente participo de discussões de assuntos como inovações, } \\
\text { processos, serviços e produtos e posso manifestar minha opinião. }\end{array}$ & 2,9 & 3 & 1,5 \\
\hline
\end{tabular}


Capacitadores do Conhecimento e Estratégias de Sobrevivência e Avanço para o Aumento da Competitividade: Estudo em uma Multinacional do Setor Alimentício.

\begin{tabular}{|l|c|c|c|}
\hline $\begin{array}{l}\text { 8. Participo de discussões que se transformam em novos conceitos, } \\
\text { compreensíveis para todos os membros que estavam envolvidos na conversa. }\end{array}$ & 2,9 & 3 & 1,5 \\
\hline Capacitador 3 - Mobilizar Ativistas do Conhecimento & $\mathbf{2 , 6}$ & $\mathbf{2 , 0}$ & $\mathbf{1 , 5}$ \\
\hline $\begin{array}{l}\text { 9. As conversas que participo na organização me inspiram a ampliar } \\
\text { conceitos e a formular novas ideias. }\end{array}$ & 2,5 & 2 & 1,5 \\
\hline $\begin{array}{l}\text { 10. Percebo que a organização estimula as pessoas a desenvolverem } \\
\text { conceitos e novas criações. }\end{array}$ & 2,5 & 2 & 1,5 \\
\hline $\begin{array}{l}\text { 11. A organização prepara as pessoas para realizarem novas tarefas que } \\
\text { necessitam do conhecimento delas. }\end{array}$ & 2,6 & 2 & 1,5 \\
\hline $\begin{array}{l}\text { 12. Vejo ações que estimulam a criação de conhecimento na organização. } \\
\text { Capacitador 4 - Criar Contexto Adequado }\end{array}$ & 2,7 & 2 & 1,6 \\
\hline $\begin{array}{l}\text { 13. Utilizo de espaços virtuais para desenvolver a criação do conhecimento } \\
\text { na organização. }\end{array}$ & 3,0 & 3 & $\mathbf{2 , 7}$ \\
\hline $\begin{array}{l}\text { 14. Posso ampliar e compartilhar sem restrição, todo conhecimento que } \\
\text { possuo da organização. }\end{array}$ & 2,8 & 3 & 1,5 \\
\hline $\begin{array}{l}\text { 15. Minha liderança me proporciona um grau de autonomia que me estimula } \\
\text { ser criativo. }\end{array}$ & 2,5 & 2 & 1,4 \\
\hline 16. Sinto-me em um ambiente de apoio para dividir meus conhecimentos. & 2,5 & 2 & 1,4 \\
\hline Capacitador 5: Globalizar o Conhecimento Local & $\mathbf{2 , 9}$ & $\mathbf{2 , 8}$ & $\mathbf{1 , 5}$ \\
\hline $\begin{array}{l}\text { 17. Percebo conhecimentos locais de outras unidades divulgados na unidade } \\
\text { onde trabalho. }\end{array}$ & 2,9 & 3 & 1,6 \\
\hline $\begin{array}{l}\text { 18. Participo de treinamentos na organização que são criados pela } \\
\text { Universidade Corporativa. }\end{array}$ & 2,6 & 2 & 1,4 \\
\hline $\begin{array}{l}\text { 19. Minha liderança expõe o meu conhecimento para outros pontos da } \\
\text { organização. }\end{array}$ & 2,9 & 3 & 1,5 \\
\hline $\begin{array}{l}\text { 20. Visito outras unidades da organização com o objetivo de adquirir e } \\
\text { receber novos conhecimentos. }\end{array}$ & 3,0 & 3 & 1,4 \\
\hline
\end{tabular}

Fonte: Dados da pesquisa.

Obs: atenção para a escala Likert utilizada: $1=$ concordância total e 5 discordância total.

Dentre os resultados mais próximos para "nem concordo e nem discordo" destacam-se:

- Questão 3 "Dentro da organização sou envolvido em discussões contendo temas que envolvem assuntos para além do escopo da minha função";

- Questão 13 "Utilizo de espaços virtuais para desenvolver a criação do conhecimento na organização e

- Questão 20 "Visito outras unidades da organização com o objetivo de adquirir e receber novos conhecimentos",

As três questões apresentaram o resultado de 3,0 para média e mediana, sinalizando que a prática das mesmas ainda não é considerada difundida pelos funcionários na organização.

Destaca-se ainda que nenhuma das questões apresentou resultados acima de 4,0, que se identificados, representariam discordância parcial ou total das afirmativas.
Em relação ao primeiro capacitador - instilar a visão do conhecimento -, os resultados sinalizam que ele é presente na PepsiCo, pois das quatro questões sobre este item, três se encontram no intervalo de 'concordância' e apenas uma delas no ponto de neutralidade (média 3). Ressalta-se que o estímulo ao compartilhamento do conhecimento, a comunicação de ideias e valores pelos gestores, que fazem com que os funcionários se sintam bem em relação ao seu cargo e a busca pela visão de futuro constituem-se em ponto positivo para a empresa, conforme depoimento do gerente de vendas. Aponta-se aqui uma reflexão sobre a oportunidade de incluir os funcionários em discussões para além do escopo de suas funções, o que pode contribuir para a formação de novas fontes de conhecimento para a empresa como um todo. O resultado ainda está alinhado aos valores da PepsiCo, que declara que "na busca pelo crescimento sustentável, procura entender se as ações de hoje contribuirão para o futuro" (PepsiCo, 2013). 
Capacitadores do Conhecimento e Estratégias de Sobrevivência e Avanço para o Aumento da Competitividade: Estudo em uma Multinacional do Setor Alimentício.

Avaliando as respostas obtidas sobre as questões do segundo capacitador gerenciar conversas, nota-se que ele é realizado de forma parcial na PepsiCo. Isso ocorre porque, apesar de a análise global em todas as questões apresentar resultados positivos para 'concordância'; na análise detalhada três das quatro questões pesquisadas apresentam oportunidades para os respondentes da área de vendas e também para os de localidade em CDV. A primeira questão do capacitador permitiu reforçar que a PepsiCo possui um ambiente que favorece a expressão de ideias e pensamentos para todos os membros da organização, desde a gerência até os níveis mais operacionais. A expressão é o pontapé inicial para que ocorra o gerenciamento das conversas e a formação das microcomunidades, que são interações face a face que permitem que os membros da empresa conheçam uns aos outros e seus campos de interesse e conhecimentos.

Considerando os resultados do terceiro capacitador para o conhecimento - mobilizar os ativistas do conhecimento, obteve-se um resultado positivo com tendência a 'concordância' em todas as questões. O resultado traz um benefício para todos os funcionários da Pepsico proporcionando o desenvolvimento deles na aquisição de novos conhecimentos e consequentemente trazendo-lhe bons resultados. Para Von Krogh et al. (2001), com a presença da mobilização dos ativistas do conhecimento, a empresa consegue gerar a motivação e integração entre os responsáveis pela criação do conhecimento. $\mathrm{O}$ resultado positivo desse capacitador também reforça os valores da PepsiCo citados na introdução, que considera o crescimento sustentável como fundamental para impulsionar e medir seu sucesso. Trata-se do crescimento das pessoas e do desempenho da companhia priorizando o "fazer a diferença" e o "fazer acontecer".

A partir das respostas das questões que avaliam o capacitador 4 - criar o contexto adequado é possível afirmar que esse contexto existe na empresa, uma vez que das quatro questões três apresentam boas porcentagens de 'concordância'. Também se evidencia, por parte de todos os respondentes, que o ambiente em que trabalham é propício à interação entre as pessoas, à troca e divisão de conhecimentos e experiências, havendo estímulo de novos conhecimentos por parte da liderança. A questão 13 foi identificada como oportunidade para a PepsiCo, considerando que o contexto capacitante pode ser gerado por interações presenciais e também virtuais, sugere-se que essas interações também ocorram através da criação de um espaço virtual. Acredita-se que, diante da área de abrangência que a empresa possui no Brasil, os espaços virtuais possam complementar e enriquecer a aproximação e a criação de conhecimentos entre funcionários de diferentes localidades.

Numa avaliação geral do capacitador globalizar o conhecimento local, embora a análise global apresente porcentagem mais alta para 'concordância', na análise detalhada foram encontrados resultados de 'discordância'. Diante desse resultado geral, considerase que esse capacitador é encontrado de forma parcial na PepsiCo, de forma mais frequente com os gerentes e profissionais com localidade no EC. Isso demonstra a necessidade de ampliação das ações desse capacitador na empresa como um todo, porém diante da elevada quantidade de funcionários e da ocorrência de localidades espalhadas pelo Brasil revela-se como um desafio e uma nova oportunidade de melhoria.

\section{Estratégias de sobrevivência e avanço}

Os resultados sinalizaram que a empresa possui em sua estratégia a preocupação tanto com a sobrevivência quanto com o avanço.

Conforme apresentado na Tabela 2, os resultados apontam um grau de concordância para esta estratégia, com uma média de 2,5 , sendo um resultado próximo à concordância parcial, confirmado pela mediana de 2,0. O desvio padrão médio foi equivalente a 1,5, indicando homogeneidade nas respostas.

Analisando os resultados da média de todas as questões em proximidade da mediana, destacam-se as questões 21 "A empresa possui um bom posicionamento de mercado em comparação aos concorrentes" e 26 "Percebo que a empresa possui processos de fabricação para novos produtos e serviços", que representam maior proximidade a concordância de sua presença na organização com o resultado de 2,2 para média e 2,0 para mediana. Tal resultado aponta que a organização preocupa-se com os concorrentes e busca sempre inovar em seus produtos e serviços.

Dentre os resultados mais próximos para nem concordo e nem discordo destaca-se a questão 28 "Percebo que a empresa possui a formação de alianças estratégicas com instituições de pesquisa e tecnologia", com o resultado de 3,0 para média, porém de 2,0 na mediana, apontando que a maioria dos respondentes revela concordância parcial para a formação das alianças.

Destaca-se ainda que nenhuma das questões apresentou resultados acima de 4,0 que, se identificados, representariam discordância total ou parcial das afirmativas. Como afirmam Von Krogh et al. (2001), para que uma organização se prepare para mudanças inesperadas em seu setor, como uma possível desvalorização dos seus atuais conhecimentos ou até mesmo a perda da utilidade de seu produto ou serviço por avanço por parte da concorrência; o equilíbrio entre as estratégias de avanço e de sobrevivência torna-se fundamental.

Numa análise geral, a partir dos resultados apresentados com alto índice de 'concordância', consideram-se presentes na PepsiCo ações que compõem sua estratégia de sobrevivência. Destaca-se 
Capacitadores do Conhecimento e Estratégias de Sobrevivência e Avanço para o Aumento da Competitividade: Estudo em uma Multinacional do Setor Alimentício.

aqui o alto índice de favorabilidade da questão que pesquisou sobre esse posicionamento; sinalizando uma forte percepção por parte dos respondentes de que a PepsiCo possui um bom posionamento. Para Von Krogh et al. (2001), esse bom posicionamento de mercado, somado à atuação da liderança focada nas necessidades imediatas e à utilização do conhecimento atual para impedir a entrada de novos concorrentes; geram força para que a empresa obtenha um melhor aproveitamento das oportunidades que se apresentam, permitindo-lhe reforçar seus pontos fortes e desenvolver seus pontos fracos a fim de atender suas necessidades do presente.

Tabela 2 - Estatísticas descritivas das estratégias

\begin{tabular}{|l|l|l|l|}
\hline & Média & Mediana & $\begin{array}{l}\text { Desvio- } \\
\text { padrão }\end{array}$ \\
\hline Estratégias de sobrevivência & $\mathbf{2 , 5}$ & $\mathbf{2 , 0}$ & $\mathbf{1 , 4}$ \\
\hline $\begin{array}{l}\text { 21. A empresa possui um bom posicionamento de mercado em } \\
\text { comparação aos concorrentes. }\end{array}$ & 2,2 & 2 & 1,1 \\
\hline $\begin{array}{l}\text { 22. A atuação da minha liderança concentra nas necessidades } \\
\text { imediatas, focando suas atividades em questões pontuais do } \\
\text { presente. }\end{array}$ & 2,7 & 2 & 1,6 \\
\hline $\begin{array}{l}\text { 24. Em geral percebo que a empresa busca dificultar a entrada } \\
\text { de novos concorrentes no mercado, utilizando do seu } \\
\text { conhecimento e experiência para atender suas necessidades. }\end{array}$ & 2,7 & 2 & \\
\hline $\begin{array}{l}\text { 25. Visando melhorias no negócio, minha empresa procura } \\
\text { reforçar seus pontos fortes e desenvolver seus pontos fracos em } \\
\text { relação ao seu conhecimento organizacional. }\end{array}$ & 2,3 & 2 & 1,5 \\
\hline Estratégias de avanço & $\mathbf{2 , 5}$ & $\mathbf{2 , 0}$ & $\mathbf{1 , 5}$ \\
\hline $\begin{array}{l}\text { 23. A atuação da minha liderança visa ações de longo prazo. } \\
\text { 26. Percebo que a empresa possui processos de fabricação para }\end{array}$ & 2,7 & 2,2 & 2 \\
\hline novos produtos e serviços. & 2,4 & 1,5 \\
\hline $\begin{array}{l}\text { 27. Em geral a empresa possui características diferenciadas de } \\
\text { experiências adquiridas nos negócios atuais para criação de } \\
\text { negócios futuros. }\end{array}$ & 2,3 & 2 & 1,3 \\
\hline $\begin{array}{l}\text { 28. Percebo que a empresa possui a formação de alianças } \\
\text { estratégicas com instituições de pesquisa e tecnologia. }\end{array}$ & 2,9 & 2 & 1,6 \\
\hline $\begin{array}{l}\text { 29. Percebo que a empresa possui ações para diminuir os } \\
\text { impactos gerados por ameaças de mudança contínua de } \\
\text { posicionamento do produto-mercado no ambiente competitivo } \\
\text { que ela se encontra. }\end{array}$ & 2,5 & 2 & 1,5 \\
\hline $\begin{array}{l}\text { 30. A empresa visa dominar o ambiente do futuro buscando } \\
\text { maneiras de influenciar a evolução do seu setor a fim de } \\
\text { aumentar seu poder de negociação sobre fornecedores e } \\
\text { clientes potenciais. }\end{array}$ & 2,4 & 2 & \\
\hline
\end{tabular}

Fonte: Dados da pesquisa.

Obs: atenção para a escala Likert utilizada: $1=$ concordância total e 5 discordância total. 
Capacitadores do Conhecimento e Estratégias de Sobrevivência e Avanço para o Aumento da Competitividade: Estudo em uma Multinacional do Setor Alimentício.

Avaliando as respostas obtidas sobre as estratégias de avanço, pode-se afirmar que a PepsiCo, na percepção de seus funcionários, evidencia sua preocupação em desenvolver essas estratégias. Todas as cinco questões utilizadas apresentaram resultados favoráveis para 'concordância', algumas em porcentagens mais altas e todas com grande equilíbrio para 'concordância' na análise por nível, área e localidade. Esse resultado evidencia que essa é uma preocupação que perpassa todos os níveis, localidades e áreas da empresa, o que pode indicar que essa preocupação já está inserida na estratégia da organização como um todo, não sendo uma tarefa de determinada área ou setor.

\section{Discussão dos resultados: capacitadores, estratégias e competitividade}

Considerando o objetivo de investigar a percepção da alta gerência em relação à contribuição dos capacitadores do conhecimento e dos referenciais estratégicos mapeados na empresa pesquisada para a sua competitividade, foi feita uma entrevista com o gerente da área de vendas, setor estratégico, que conta com cerca de 12.000 mil funcionários. O gerente reconheceu, primeiramente, que a organização possui um ambiente favorável à troca de experiências e ao incentivo à criação do conhecimento. Para ele, isso pode ser percebido de diversas formas, entre elas pelo estímulo dado a todos os funcionários da empresa, independente do nível e posição que ocupam, para que eles expressem suas opiniões para as outras pessoas da empresa, programa chamado de "portas abertas", Um dos resultados é a satisfação proporcionada aos funcionários que tiveram suas opiniões e conhecimentos escutados e implementados. O uso do modelo autogerenciável presente nas fábricas, que partiu da ideia de funcionários, contribuiu para bons resultados na produtividade.

$\mathrm{O}$ entrevistado confirmou a presença dos capacitadores instilar a visão do conhecimento, gerenciar conversas e criar um contexto adequado e citou alguns resultados que contribuem para a competitividade da organização, entre eles: a liderança de mercado que a empresa possui; o uso das ideias e opiniões de funcionários, que faz com que a empresa avance gerando credibilidade no mercado e a incorporação das mudanças e melhorias de produtos no negócio, possibilitando diferenciais competitivos à organização. Estes fatos indicam resultados proporcionados por uma estratégia de sobrevivência desenvolvida.

Sobre a importância da inovação, destaca-se sua percepção: "a empresa tem que inovar mesmo, porque ela é líder e dita as regras do mercado". Relatou o uso do conhecimento das pessoas na organização para melhoria contínua na inovação de processos e produtos da empresa. Ressaltou a necessidade do uso de espaços virtuais para catalizar a aprendizagem, já evidenciado na pesquisa quantitativa. Dentre eles estão: o uso da TV corporativa presente nas unidades.

Sobre as contribuições dos capacitadores do conhecimento e das estratégias de sobrevivência e avanço para a competitividade da organização, objetivo geral da pesquisa, foi possível identificar os itens constantes da Tabela 1.

Sobre os capacitadores 1 - instilar a visão do conhecimento - e 2 - gerenciar conversas - a empresa apresentou o incentivo, dado pelos gestores, ao compartilhamento do conhecimento e à comunicação de ideias e valores que favorecem a criação de conhecimentos. Quando utilizados, os conhecimentos possibilitam a transformação e criação de produtos e serviços, sendo esse é um fator favorável para a competitividade da empresa. Na PepsiCo, a confirmação desse resultado pode ser comprovada pela alta porcentagem de concordância à questão "Percebo que a empresa possui processos de fabricação para novos produtos e serviços" e pela fala do gerente da área de vendas, quando citou exemplos de produtos inovadores, como o Doritos, e expressou a preocupação da empresa em modificar os processos com base nas opiniões dos funcionários. Este resultado ainda está de acordo com os valores da empresa, que declara visar um ambiente de trabalho que inclui pessoas com diferentes características e modos distintos de pensar. Para ela, isso leva à inovação e à capacidade de identificar novas oportunidades de mercado, ajudando no desenvolvimento de novos produtos e fortalecendo o compromisso de crescer através de pessoas com autonomia.

É possível identificar (Figura 1) que a prática da criação de novos produtos e serviços contribui para alimentação da estratégia de sobrevivência da empresa pesquisada, sendo fundamental para proporcionar sua rentabilidade, principalmente no presente, trazendo retorno competitivo pelo domínio sobre o cenário atual dos negócios gerados. Esse resultado pode ser confirmado pela alta favorabilidade da questão "A empresa possui um bom posicionamento de mercado em comparação aos concorrentes" e pelos relatos do gerente.

Partindo das contribuições do capacitador 3 mobilizar os ativistas do conhecimento -, foi possível perceber que existem dentro da PepsiCo ativistas que inspiram a ampliação de conceitos e estimulam a formulação de novas ideias entre as pessoas. A criação de novos conceitos resulta na melhoria contínua do conhecimento da empresa, o que contribui diretamente para a inovação de seus processos e produtos, possibilitando a ocorrência da inovação radical. que alimenta a estratégia de avanço e constitui uma fonte diferenciada de competitividade, por possibilitar algo não implementado pelos concorrentes, produzindo 
Capacitadores do Conhecimento e Estratégias de Sobrevivência e Avanço para o Aumento da Competitividade: Estudo em uma Multinacional do Setor Alimentício.

vantagens originais, trazendo rentabilidade futura e posicionamento diferenciado de mercado. Este resultado é comprovado pela concordância na questão: "Em geral a empresa possui características diferenciadas de experiências adquiridas nos negócios atuais para criação de negócios futuros" somados ao exemplo de inovação radical citada pelo gerente sobre o projeto de mudança de modelo de atendimento, considerado como "fortaleza" da empresa.

Considerando o capacitador 4 - criar o contexto adequado -, com a presença do ambiente para a criação de rede de relacionamentos e interações que unifica os espaços mentais dos envolvidos na criação e evolução do conhecimento, a pesquisa sinalizou que os funcionários podem compartilhar seus conhecimentos sem restrição. Os resultados obtidos com a evolução do conhecimento, em melhoria contínua, dificultam a entrada de novos concorrentes no mercado, mantendo a estratégia de sobrevivência da organização. Essa constatação foi confirmada pelo resultado de concordância à questão "Em geral percebo que a empresa busca dificultar a entrada de novos concorrentes no mercado".

Figura 1 - Uso dos capacitadores e das estratégias para a competitividade da empresa

\begin{tabular}{|c|c|c|c|}
\hline Capacitador & Resultados & Estratégia & $\begin{array}{l}\text { Contribuições para a } \\
\text { competividade }\end{array}$ \\
\hline $\begin{array}{l}\text { Instilar a visão do } \\
\text { conhecimento e } \\
\text { Gerenciar as } \\
\text { conversas. }\end{array}$ & $\begin{array}{l}\text { Geração e estoque de novos } \\
\text { conhecimentos; } \\
\text { Transformação e criação de } \\
\text { novos produtos e serviços; } \\
\text { Inovação incremental. }\end{array}$ & Sobrevivência & $\begin{array}{c}\text { Liderança de mercado; } \\
\text { Rentabilidade no presente. }\end{array}$ \\
\hline $\begin{array}{l}\text { Mobilizar os } \\
\text { ativistas do } \\
\text { conhecimento }\end{array}$ & $\begin{array}{l}\text { Formulação de novas ideias; } \\
\text { Melhoria contínua; } \\
\text { Inovação radical. }\end{array}$ & Avanço & $\begin{array}{c}\text { Algo não implementado } \\
\text { pelos concorrentes; } \\
\text { Características } \\
\text { diferenciadas para negócios } \\
\text { futuros; } \\
\text { Rentabilidade futura. }\end{array}$ \\
\hline $\begin{array}{c}\text { Criar o contexto } \\
\text { adequado }\end{array}$ & $\begin{array}{c}\text { Criação e evolução do } \\
\text { conhecimento; Autonomia e } \\
\text { criatividade; } \\
\text { Melhoria contínua para atender } \\
\text { suas necessidades. }\end{array}$ & $\begin{array}{l}\text { Sobrevivência e } \\
\text { Avanço }\end{array}$ & $\begin{array}{c}\text { Dificulta a entrada de } \\
\text { novos concorrentes; } \\
\text { Vantagens originais nos } \\
\text { produtos e serviços. }\end{array}$ \\
\hline $\begin{array}{c}\text { Globalizar o } \\
\text { conhecimento } \\
\text { local }\end{array}$ & $\begin{array}{l}\text { Disseminação de } \\
\text { conhecimentos; } \\
\text { Nivelamento do conhecimento; } \\
\text { Inovações. }\end{array}$ & Avanço & $\begin{array}{c}\text { Adaptação às } \\
\text { circunstâncias locais; } \\
\text { Vantagens originais; } \\
\text { Aumento do poder de } \\
\text { negociação; } \\
\text { Posicionamento } \\
\text { diferenciado no mercado. }\end{array}$ \\
\hline
\end{tabular}

Fonte: dados da pesquisa.

Avaliando o capacitador 5 - globalizar o conhecimento local -, foi possível observar ações para compartilhar o conhecimento local de forma global, mesmo presente apenas em alguns níveis e localidades, À medida que as várias unidades usam o conhecimento e o adaptam às suas circunstâncias locais, a vantagem competitiva aumenta para a organização como um todo. A contribuição para a inovação, gerada pela globalização do conhecimento na organização, influencia diretamente o desenvolvimento da estratégia de avanço, Esse resultado foi identificado pela concordância à questão "A empresa visa dominar o ambiente do futuro buscando maneiras de influenciar a evolução do seu setor a fim de aumentar seu poder de negociação sobre fornecedores e clientes potenciais".

Por meio da análise realizada, foram constatadas diversas contribuições, tanto por parte dos capacitadores do conhecimento, quanto por parte das estratégias de sobrevivência e de avanço para a competitividade da PepsiCo. 
Capacitadores do Conhecimento e Estratégias de Sobrevivência e Avanço para o Aumento da Competitividade: Estudo em uma Multinacional do Setor Alimentício.

\section{CONSIDERAÇÕES FINAIS}

O estudo realizado buscou identificar e analisar as contribuições dos capacitadores do conhecimento e das estratégias de sobrevivência e avanço para a competitividade na PepsiCo. A pesquisa sinalizou a presença de todos os capacitadores na empresa, uns com mais intensidade que outros.

Dentre aqueles que apresentaram melhores resultados destacam-se os capacitadores: 1) instilar a visão do conhecimento, 3) mobilizar os ativistas do conhecimento e 4) criar o contexto capacitante. Os capacitadores 2) gerenciar as conversas e 5) globalizar $o$ conhecimento, foram considerados oportunidades para a melhoria, pois foram identificados de forma parcial.

O capacitador 3 pode ser considerado como ponto forte. Foi possível perceber que existem dentro da PepsiCo ativistas que inspiram a ampliação de conceitos e estimulam a formulação de novas ideias entre as pessoas. A criação de novos conceitos resulta na melhoria contínua do conhecimento da empresa, o que contribui diretamente para a inovação de seus processos e produtos, possibilitando a ocorrência da inovação radical. Por sua vez, a inovação radical alimenta a estratégia de avanço e constitui uma fonte diferenciada de competitividade, por possibilitar algo não implementado pelos concorrentes, produzindo vantagens originais e gerando impacto para rentabilidade futura. Esse capacitador exerce uma grande influência na organização, possibilitando a motivação e integração entre os responsáveis pela criação do conhecimento. Em consequência, estes ajudam a promover um ambiente capacitante adequado, que por sua vez estimula a liberação e o nivelamento do conhecimento em toda a empresa.

O capacitador 1 pôde ser identificado pelo incentivo dado pelos gestores, ao compartilhamento do conhecimento e à comunicação de ideias e valores que favorecem a criação de conhecimentos tácitos. Quando utilizados, os conhecimentos possibilitam a transformação e criação de produtos e serviços, sendo esse um fator favorável para a competitividade da empresa. Este resultado ainda está de acordo com os valores da empresa, que declara visar um ambiente de trabalho que inclui pessoas com diferentes características e modos distintos de pensar. Para ela, isso leva à inovação e à capacidade de identificar novas oportunidades de mercado, ajudando no desenvolvimento de novos produtos e fortalecendo o compromisso de crescer através de pessoas com autonomia.

Já o capacitador 4 pôde ser identificado com a presença de um ambiente para a criação de rede de relacionamentos e interações que unifica os espaços mentais dos envolvidos na criação e evolução do conhecimento. A pesquisa mostrou que os funcionários na PepsiCo podem compartilhar seus conhecimentos sem restrição. A liderança estimula a autonomia em seus funcionários, propiciando a criatividade individual ou coletiva. É possível considerar que ele contribui para o avanço da empresa, uma vez que o diferencial gerado em seu setor de atuação fortalece seu posicionamento de mercado, trazendo vantagem competitiva para a organização.

Os capacitadores 2 e 5 encontrados de forma parcial e considerados pontos para melhoria, merecem uma atenção e devem ser mais bem desenvolvidos. $\mathrm{O}$ capacitador 2 , gerenciador de conversas, é importante para que a empresa envolva, de forma equilibrada, todos os níveis, áreas e localidades presentes. Foi possível identificar ações para compartilhar o conhecimento local de forma global, mesmo presente apenas em alguns níveis e localidades. À medida que as várias unidades usam o conhecimento e o adaptam às suas circunstâncias locais, a vantagem competitiva aumenta para a organização como um todo. A contribuição para a inovação, gerada pela globalização do conhecimento na organização, influencia diretamente o desenvolvimento da estratégia de avanço, produzindo vantagens originais e trazendo rentabilidade futura e posicionamento diferenciado de mercado.

Enfim, a partir dos resultados apresentados, pode-se concluir que os capacitadores do conhecimento e as estratégias de sobrevivência e avanço, identificadas na PepsiCo, contribuem efetivamente para sua competitividade, segundo o modelo de Von Krogh et al. (2001). Os autores ressaltam que, para uma organização se preparar para mudanças inesperadas, como uma possível desvalorização dos seus atuais conhecimentos ou até mesmo a perda da utilidade de seus produtos ou serviços, por entrada da concorrência no mercado, o equilíbrio entre as estratégias de avanço e de sobrevivência torna-se fundamental.

Como limitação desta pesquisa aponta-se a aplicação da entrevista a apenas um gerente da empresa. Sugere-se entrevistas com outros gerentes, que poderiam complementar com mais riqueza a discussão dos resultados, mostrando a visão de representantes de outras áreas e localidades da empresa.

Considera-se que esta pesquisa contribui para a Academia, uma vez que amplia as discussões sobre a importância dos capacitadores do conhecimento e das estratégias de sobrevivência e avanço, apontando suas ligações com a competitividade. Ressalta-se também a verificação de resultados gerados pela aplicabilidade do modelo de Von Krogh et al. (2001) e a criação de um instrumento de coleta de dados que poderá ser utilizado por outros pesquisadores.

A pesquisa proporcionou para a PepsiCo um diagnóstico, que sinalizou seus diferenciais competitivos e posição frente ao mercado, com base nos investimentos na criação, uso e melhoria contínua de seu conhecimento. 
Capacitadores do Conhecimento e Estratégias de Sobrevivência e Avanço para o Aumento da Competitividade: Estudo em uma Multinacional do Setor Alimentício.

Para os autores, o resultado permitiu uma maior compreensão da dinâmica do mercado e do papel do conhecimento nas estratégias de sobrevivência e avanço. Proporcionou também a possibilidade de vincular a teoria à prática sinalizando ações que trazem

\section{REFERÊNCIAS}

Alvarenga Neto, R C D; Barbosa, R R \& Pereira, H J (2007). Gestão do conhecimento ou gestão de organizações da era do conhecimento? Um ensaio teórico-prático a partir de intervenções brasileiras. Perspectivas em Ciência da informação, v. 12, n.1, p. 5-24, jan./abr.. Disponível em: <http://www.scielo.br/pdf/pci/v12n1/01.pdf>. Acesso em: 25 fev. 2013.

Bardin, L; (2009). Análise de Conteúdo. Lisboa, Portugal; Edições 70, LDA.

Braga, C R A; Vasconcelos, M C R L; Maccari, E A \& Neves, J T R. (2014). Estratégias de Sobrevivência e Avanço Numa Organização do Terceiro Setor: O Papel dos Capacitadores do Conhecimento na Junior Achievement de Minas Gerais. Revista Iberoamericana de Estratégia, v. 13, p. 109-122.

Cardoso, L; (2007) Gestão do Conhecimento e competitividade organizacional: Um modelo estrutural. Comportamento Organizacional e Gestão. v. 13, n. 2 , p. 191-211,. Disponível em: <http://www.scielo.gpeari.mctes.pt/pdf/cog/v13n2/v13 n2a04.pdf>. Acesso em: 25 fev. 2013.

Crawford, R; (1994). Na Era do Capital Humano. São Paulo: Atlas.

Choo, C. W. (2003). A Organização do Conhecimento: como as organizações usam a informação para criar significado, construir conhecimento e tomar decisões. São Paulo: Editora Senac São Paulo.

Collis, J \& Hussey, R; (2005). Pesquisa em administração: um guia prático para alunos de graduação e pós-graduação. 2. ed. Porto Alegre: Bookman.

Davenport, T \& Prusak, L (1998). Conhecimento empresarial: como as organizações gerenciam o seu capital intelectual. Tradução Lenke Peres. Rio de Janeiro: Campus.

Gonçalves, S F R; (2010) Gestão do Conhecimento: análise de práticas e ferramentas no âmbito da Administração Tributária de Minas Gerais. 162 f. Dissertação (Mestrado Profissional em Administração) resultados positivos os quais representam oportunidades que precisam ser reforçadas e trabalhadas.

- Faculdades Integradas Pedro Leopoldo, Pedro Leopoldo, Minas Gerais.

Gonçalves, S F R; Vasconcelos, M C R L; Carvalho, R B \& Neves, J T. (2012). Práticas e Ferramentas de Gestão do Conhecimento no Âmbito da Administração Tributária de Minas Gerais: Oportunidade para uma Política Institucional. Revista de Gestão e Projetos, v. 3, p. 207-234.

Nonaka, I \& Takeuchi, H; (1997). Criação de conhecimento na empresa. Tradução Ana Beatriz Rodrigues e Priscilla Martins Celeste. Rio de Janeiro: Campus.

PepsiCo (2013). Programa de Integração PepsiCo. Apresentação institucional de uso interno. Formato digital em PowerPoint.

Pereira, A A; Pereira, F C M; Vasconcelos, M C R L \& Ferreira, M A T (2015). O Contexto Capacitante e a Construção do Conhecimento Organizacional: Um Estudo de Caso sobre Condições Capacitadoras e Capacitadores na DICON/UFSJ. Revista Gestão \& Tecnologia, v. 15, p. 276-297.

Probst, G; Raub, S \& Romhart, K; (2002). Gestão do Conhecimento: os elementos construtivos do sucesso. Porto Alegre: Bookman.

Santos, A E M \& Popadiuk, S; (2010) A gestão do conhecimento e a capacidade de competição. Contextus, Revista Contemporânea de Economia $e$ Gestão. v. 8, n.1, p. 21-32, jan./jun. Disponível: <http://www.contextus.ufc.br/index.php/contextus/arti cle/view/254/0>. Acesso em: 25 fev. 2013.

Terra, J C C; (2005). Gestão do conhecimento. $O$ grande desafio empresarial: uma abordagem baseada no aprendizado e na criatividade. São Paulo: Negócio.

Vasconcelos, M C R L; (2000). Cooperação universidadelempresa na pós-graduação: contribuição para a aprendizagem, gestão do conhecimento $e$ inovação da indústria mineira. 257f. Tese (Doutorado em Ciência da Informação). Universidade Federal de Minas Gerais - UFMG. Belo Horizonte, Minas Gerais. 
Capacitadores do Conhecimento e Estratégias de Sobrevivência e Avanço para o Aumento da Competitividade: Estudo em uma Multinacional do Setor Alimentício.

Von Krogh, G; Ichijo K \& Nonaka I; (2001). Facilitando a criação do conhecimento. Rio de Janeiro: Campus.
Yin, R K; (2001). Estudo de caso: planejamento e métodos. Tradução de Daniel Grassi. 2. ed. Porto Alegre: Bookman. 